\title{
Nuclear factor-кB and advanced glycation end-products expression in lacrimal glands of aging rats
}

\author{
M Alves ${ }^{1}$, D Andrade Cunha ${ }^{2}$, V Cristine Calegari ${ }^{1}$, M J A Saad ${ }^{1}$, \\ A Carlos Boschero ${ }^{2}$, L Augusto Velloso ${ }^{1}$ and E Melani Rocha ${ }^{1,3}$ \\ ${ }^{1}$ Laboratory of Clinical Physiopathology, Department of Clinical Medicine, School of Medicine, State University of Campinas (UNICAMP), Campinas, Brazil \\ ${ }^{2}$ Institute of Biology, State University of Campinas (UNICAMP), Campinas, Brazil \\ ${ }^{3}$ Department of Ophthalmology, São Paulo University, Ribeirão Preto, Sao Paulo, Brazil \\ (Requests for offprints should be addressed to E M Rocha, Departamento de Oftalmologia, FMRP, Universidade de São Paulo, 14049-900 Ribeirão Preto, \\ SP, Brazil; Email: emrocha@fmrp.usp.br)
}

\begin{abstract}
Advanced glycation end products (AGEs) increase with aging and induce signaling alterations that lead to inflammation and dysfunction in several tissues. Aging reduces function and insulin signaling in lacrimal glands (LGs). To evaluate whether AGE signaling and insulin secretion in LGs are altered in aging, 24- and 2-month-old male Wistar rats were compared. Immunohistochemistry with confocal microscopy was used to evaluate AGE, AGE receptor (RAGE) and nuclear factor- $\kappa \mathrm{B}(\mathrm{NF}-\mathrm{\kappa B})$ expression in LGs. Basal tear secretion volume, insulin, interleukin-1 $\beta$ (IL-1 $\beta$ ) and tumor necrosis factor- $\alpha$ (TNF- $\alpha$ ) levels in tears and LGs and peroxidase activity in LG tissue were measured. Insulin secretion from isolated LGs and pancreatic $\beta$-cells was compared in the supernatant of aging and control rats in vitro by RIA after stimulation with $2 \cdot 8-16.7 \mathrm{mM}$ glucose, carbachol and
\end{abstract}

KCl. AGE, RAGE and NF- $\mathrm{KB}$ expression was higher in LGs of aging compared with young rats. Basal tear secretion and peroxidase activity were significantly lower in the aging group ( $P=0.016$ for both assays). IL-1 $\beta$ and TNF- $\alpha$ levels were higher in tears of aging rats compared with young rats $(P=0.007$ and 0.05 respectively); however, even though aging rats were insulin-resistant (as confirmed by the insulin-tolerance test), the insulin levels in the tear film of aging and control rats were similar in vivo and in vitro. The higher expression of AGEs, RAGE and $\mathrm{NF}-\kappa \mathrm{B}$ in LGs of aging rats is accompanied by systemic insulin resistance and may be involved in LG and tear film alterations but does not affect insulin secretion in the tear film. These observations indicate that metabolic events may be related to LG and tear film dysfunctions in aging. Journal of Endocrinology (2005) 187, 159-167

\section{Introduction}

It has been demonstrated that the process of aging is accompanied by morphological and secretory changes in lacrimal glands (LGs) that correlate with manifestations of dry eye (McGill et al. 1984, Bromberg \& Welch 1985, Mathers et al. 1996, Schein et al. 1997, Draper et al. 1999, 2003). Among the pathophysiological mechanisms that underlie these changes, two possible events are the impairment of the mechanisms of insulin signal transduction (Carvalho et al. 1996, Rocha et al. 2003) and the formation of advanced glycation end products (AGEs), as also observed in other tissues (Vlassara et al. 1994, Stitt 2001). Taken together, these two hypotheses may predict that metabolic events, like insulin resistance, induce AGE accumulation in aging tissues and signaling alterations, leading to dysfunction in the secretory mechanisms of LGs.

Metabolic alterations involving early elements of the signaling cascades may be related to insulin reduction or resistance and consequent organ dysfunctions in old rats (Castro et al. 1993, Perfetti et al. 1995, Paez-Espinosa et al. 1999, Rocha et al. 2004). One of the major consequences of insulin resistance, as observed in the elderly, is chronic hyperglycemia and oxidative stress leading to the formation of AGEs, obtained from chemical reaction of carbohydrates with proteins (Pongor et al. 1984, Singh et al. 2001, Evans et al. 2002). Previous studies have shown that AGEs alter the structure and functions of proteins, including those involved in cell signaling, and contribute to the chronic complications of aging (Vlassara et al. 1994, Zarina et al. 2000, Stitt 2001, Portero-Otin et al. 2002).

AGE binding to its receptor (RAGE) leads to the activation of the transcription factor nuclear factor- $\mathrm{KB}$ $(\mathrm{NF}-\mathrm{\kappa B})$, which allows its translocation to the nucleus, where it regulates the expression of a large number of genes, including tumor necrosis factor- $\alpha$ (TNF- $\alpha$ ), interleukin-1 $\beta$ (IL-1 $\beta$ ) and RAGE (Singh et al. 2001, Evans et al. 2002). IL-1 $\beta$ and TNF- $\alpha$ mRNAs are 
expressed in LGs of animal models with exocrine gland inflammatory dysfunction and on the ocular surface of patients with dry eye syndrome, supporting the possible involvement of such cytokines in LG dysfunction in aging (Rocha et al. 1998, Solomon et al. 2001). In addition, IL-1 $\beta$ and TNF- $\alpha$ are known to influence the function of LG tissues (Zoukhri et al. 2002). Therefore, the mechanisms by which hyperglycemia and oxidative stress act in age-related LG dysfunction might involve the formation of AGEs and activation of NF- $\mathrm{KB}$ in the LGs, interfering with the signaling pathways and intracellular activity of cytokines such as IL- $1 \beta$ and TNF- $\alpha$.

Insulin is a powerful inotrophic element for LGs in culture (Hann et al. 1991). It is present in the tear film, and insulin receptors (IRs) have been demonstrated in LGs (Hann et al. 1991, Rocha et al. 2000). In rats, insulin secretion from pancreatic islet cells (Castro et al. 1993, Perfetti et al. 1995) and the secretory response of LGs are impaired by aging (Draper et al. 2003). It is unknown whether insulin secretion is reduced in aging LGs following the secretory dysfunctions observed in these tissues.

In order to assess the involvement of insulin and AGE-related metabolic pathways in the pathogenesis of LG dysfunction in the elderly, the objectives of the present study were to identify the effects of aging on (i) LG expression of NF- $\mathrm{KB}$, AGEs and RAGEs, (ii) LG and tear content of the proinflammatory cytokines IL-1 $\beta$, and TNF- $\alpha$, and (3) LG patterns of insulin secretion.

\section{Material and Methods}

\section{Animal model}

Male Wistar rats aged 2 months (young) and 24 months (aging) provided by the university's (UNICAMP) Animal Breeding Center received standard rodent chow and water ad libitum. Food was withdrawn $12-14 \mathrm{~h}$ before the experiments. All experimental procedures adhered to the UFAW Handbook on the Care and Management of Laboratory Animals and FRAME's guidelines and were approved by the Ethics Committee of the State University of Campinas (UNICAMP).

\section{Immunohistochemistry}

Exorbital lacrimal glands were excised from young and aging rats, embedded in Tissue Tek OCT (optimal cutting temperature) compound (Sakura Fine Tek, Torrance, CA, USA), frozen in liquid nitrogen and stored at $-80{ }^{\circ} \mathrm{C}$. Tissue specimens were cut using a cryostat into $7 \mu \mathrm{m}$ sections at $-20{ }^{\circ} \mathrm{C}$ and transferred to poly-L-lysine precoated glass slides (Perfecta, São Paulo, SP, Brazil). The slides were exposed to acetone for $10 \mathrm{~min}$, washed in PBS $(0 \cdot 1 \mathrm{M}$ sodium phosphate and $0 \cdot 15 \mathrm{M} \mathrm{NaCl}, \mathrm{pH} 7 \cdot 4$; Sigma Chemical Co., St Louis, MO, USA) and exposed to
$3 \%$ BSA solution (Sigma) for $1 \mathrm{~h}$ at $22^{\circ} \mathrm{C}$ to reduce nonspecific protein binding. The sections were overlaid with rabbit polyclonal anti-NF- $\kappa \mathrm{B}$ subunit p65 antibody (Santa Cruz Biotechnologies, Santa Cruz, CA, USA), anti-AGE mouse monoclonal antibody (Research Diagnostic, Flanders, NJ, USA) or anti-RAGE rabbit polyclonal antibody (Santa Cruz Biotechnologies) at $4 \mu \mathrm{g} / \mu \mathrm{l}$ concentration with 1\% BSA in PBS. Following overnight incubation with primary antibody in a humidified chamber, the sections were washed in PBS and incubated for $2 \mathrm{~h}$ with anti-rabbit or anti-mouse IgG antibody conjugated with fluorescein isothiocyanate (FITC; Jackson Immunoresearch Laboratories, West Grove, PA, USA) at a concentration of $375 \mu \mathrm{g} / \mu \mathrm{l}$ in 1\% BSA. After incubation with the secondary antibody, sections were again washed and counterstained with phalloidin (Sigma) concentrated to $0 \cdot 1 \mu \mathrm{g} / \mu \mathrm{l}$ for $45 \mathrm{~min}$ in a dark chamber. The slides were covered with Vectashield (Vector Laboratories, Burlingame, CA, USA) and a coverslip. Photographic documentation was performed using a confocal Zeiss Axiovert $200 \mathrm{M}$ microscope (Zeiss, Wetzlar, Germany).

\section{Determination of the expression of $N F-\kappa B$ in nuclear and cytoplasmic extracts of LGs}

Western blot studies to evaluate the expression of NF- $\kappa \mathrm{B}$ were performed on nuclear and cytoplasmic extracts of both study groups as described previously (Vaisse et al. 1996, Rocha et al. 2000). In summary, nuclear and cytoplasmic extracts were obtained from the exorbital LGs of young and aging rats ( $n=6 /$ group per experiment), collected under thiopental anaesthesia, and the tissues were coarsely minced and homogenized. The homogenate was centrifuged at $2000 \mathrm{~g}$ for $10 \mathrm{~min}$ at $4{ }^{\circ} \mathrm{C}$ in an Eppendorf centrifuge $5804 \mathrm{R}$, and the pellet was washed and resuspended in buffer A before being centrifuged again at the same speed for $10 \mathrm{~min}$. The supernatant corresponded to the cytoplasmic extract. The pellet was then resuspended in a buffer B and then sonicated 10 times in a PotterElvehjem homogenizer (Kimble Kontes, Vineland, NJ, USA) with vigorous shaking for $30 \mathrm{~min}$, and then centrifuged at $16000 \mathrm{~g}$ for $30 \mathrm{~min}$. The supernatant corresponded to the nuclear extract. The protein quantification was performed and equal amounts of protein $(150 \mu \mathrm{g})$ were used for each sample in the Western blot studies. Samples were treated with Laemmli buffer and were subjected to SDS/PAGE (10\% Tris/acrylamide) in a Bio-Rad miniature slab gel apparatus (Miniprotean; BioRad Laboratories, Richmond, CA, USA), in parallel with pre-stained protein standards and $\beta$-mercaptoethanol (Bio-Rad, Hercules, CA, USA). Proteins were then electrotransferred from the gel to a Hybond ECL nitrocellulose membrane (Amersham Biosciences, Little Chalfont, Bucks, UK) for $2 \mathrm{~h}$ at $120 \mathrm{~V}$ in a Bio-Rad miniature transfer apparatus (Miniprotean). After blocking, the membranes were then incubated overnight with 
rabbit polyclonal anti-NF- $\mathrm{\kappa B}$ subunit $\mathrm{p} 65$ at a concentration of $0.4 \mu \mathrm{g} / \mu \mathrm{l}$ in a buffer with $3 \%$ BSA, and then washed three times as described above. The blots were then incubated with ${ }^{125}$ I-Protein A (Amersham Biosciences) and detected by autoradiography. Images of developed autoradiographs were scanned, and band intensities were quantified by optical densitometry using image-analysis software (Scion Image Analysis Software; Scion Corp, Frederick, MD, USA).

\section{Determination of tear volume and of $I L-1 \beta, T N F-\alpha$ and insulin content in tears}

Tear volume was measured in the animals of both study groups anaesthetized with an i.p. injection of sodium thiopental $(100 \mu \mathrm{g} / \mathrm{kg}$; Cristália, Itapira, SP, Brazil) and used 10-15 min later, as soon as anaesthesia was assured by the loss of foot and corneal reflexes, using micropipettes (Eppendorf Research, Hamburg, Germany), and tears were collected and measured from the lacrimal meniscus, with an attempt made to collect the whole volume in one take and to avoid stimuli.

IL- $1 \beta$ and TNF- $\alpha$ were measured in tears collected from aging and control rats with an ELISA kit according to the manufacturer's instructions (Pierce Endogen, Rockford, IL, USA). Tear samples from both eyes were pooled together.

For analysis of insulin secretion in tear film, tear samples were collected from rats fasted for $12 \mathrm{~h}$. Tears were collected with graduated Pasteur pipettes from the ocular surface with minor manipulation, pooled from both eyes and transferred to Eppendorf tubes containing $50 \mu \mathrm{l} 0.9 \%$ $\mathrm{NaCl}$. The samples were frozen at $-75^{\circ} \mathrm{C}$ until the RIA, as described previously (Rocha et al. 2002a).

\section{Plasma glucose disappearance test $\left(K_{I T T}\right)$}

To evaluate the plasma glucose disappearance rate in response to insulin injection, a test also known as the insulin-tolerance test, rats from both groups were anaesthetized with an i.p. injection of sodium thiopental, $100 \mu \mathrm{g} / \mathrm{kg}$ body weight, and used $10-15 \mathrm{~min}$ later, as soon as anaesthesia was assured by loss of foot and corneal reflexes. Blood samples were collected from a caudal vein at 0 (basal glucose determination), 4, 8, 12 and $16 \mathrm{~min}$ after i.v. injection of $10 \mu \mathrm{M}$ insulin. The samples were analyzed by a glucose oxidase method (Labtest, Lagoa Santa, MG, Brazil). Plasma glucose disappearance rate $\left(\mathrm{K}_{\text {ITT }}\right)$ was calculated by the formula $0 \cdot 693 / t_{1 / 2}$. Plasma glucose half-life $\left(t_{1 / 2}\right)$ was calculated from the slope of the least-squares analyses of the plasma glucose concentrations during the linear phase of decline, as described previously (Rocha et al. 2002b).

\section{Peroxidase assay}

To compare peroxidase activity in LG samples from aging and young rats, the tissues were exposed to a protocol described previously (Stoppiglia et al. 2002). Briefly, samples were homogenized in Hanks solution at $4{ }^{\circ} \mathrm{C}$ and the homogenates were centrifuged at $10000 \mathrm{~g}$ for $8 \mathrm{~min}$ to remove cell membranes and organelles. The protein concentration of the supernatant was measured by the Biuret dye method (Labtest) and samples were collected and completed with Hanks solution to obtain $100 \mu \mathrm{g} / \mathrm{ml}$ protein. $\mathrm{H}_{2} \mathrm{O}_{2}$ was added at a final concentration of $4.4 \mathrm{mM}$ to each sample and controls were run in parallel. Aliquots were collected at 0, 5, 10, 20, 30, 40 and $60 \mathrm{~min}$ and peroxidase activity was measured by colorimetry (Glucose GODPAP, Laborlab, Brazil), against a $\mathrm{H}_{2} \mathrm{O}_{2}$ standard curve. Values were fitted with single exponential decay curves according to the formula:

$$
\left[\mathrm{H}_{2} \mathrm{O}_{2}\right] \cdot(t)=\left[\mathrm{H}_{2} \mathrm{O}_{2}\right]_{t=0} \times \mathrm{e}^{-\mathrm{kt}}
$$

The peroxidase activity of each sample is represented by the $k$ value $\left(\left[\mathrm{H}_{2} \mathrm{O}_{2}\right]\right.$ decay constant) obtained, expressed in $\mu \mathrm{M} / \mathrm{min}$.

\section{In vitro insulin secretion}

Under anaesthesia, the pancreas and LGs were removed from young and aging rats. The tissues were incubated in Krebs bicarbonate buffer on separate Petri dishes for each experimental group and tissue. The pancreatic tissue was digested with collagenase to allow islet isolation, as described by Boschero et al. (1995) and LG tissue was cut into fragments with a mean diameter of $1 \mathrm{~mm}$ under a microscope using fine scissors. LG samples consisted of groups of two LG fragments that were first incubated in cell strainers for $45 \mathrm{~min}$ at $37^{\circ} \mathrm{C}$ in Krebs bicarbonate buffer containing $5.6 \mathrm{mM}$ glucose and equilibrated with $95 \% \mathrm{O}_{2} / 5 \% \mathrm{CO}_{2}, \mathrm{pH} 7 \cdot 4$. Samples of five islets were run in parallel for comparison. The solution was then replaced with fresh Krebs bicarbonate buffer and the islets were further incubated for $1 \mathrm{~h}$ with media of the following composition: $2 \cdot 8,8 \cdot 3$ or $16.7 \mathrm{mM}$ glucose, $16.7 \mathrm{mM}$ glucose combined with $20 \mu \mathrm{g} / \mathrm{ml}$ diazoxide, $200 \mathrm{mM}$ carbachol, and $200 \mu \mathrm{M}$ carbachol combined with $66 \mu \mathrm{g} / \mathrm{ml}$ atropine or $40 \mathrm{mM} \mathrm{K}^{+}$. The incubation medium contained $115 \mathrm{mM} \mathrm{NaCl}, 5 \mathrm{mM} \mathrm{KCl}, 24 \mathrm{mM} \mathrm{NaHCO}_{3}$, $2.56 \mathrm{mM} \mathrm{CaCl}_{2}, 1 \mathrm{mM} \mathrm{MgCl}$ and $3 \mathrm{~g} / 1 \mathrm{BSA}$.

After the incubation period, the supernatant of each condition ( $n=5 /$ condition) and negative controls were collected and processed by RIA. To measure the total content of insulin in LGs and isolated islets, samples were homogenized with polytron PT1200C (Brinkmann Instruments, New York, NY, USA) in alcohol/acid solution $(20 \%$ ethanol and $0 \cdot 2 \mathrm{M} \mathrm{HCl})$ and also processed for RIA.

\section{Insulin quantification}

The insulin content in tears, plasma, supernatant from in vitro experiments and homogenized tissues were 

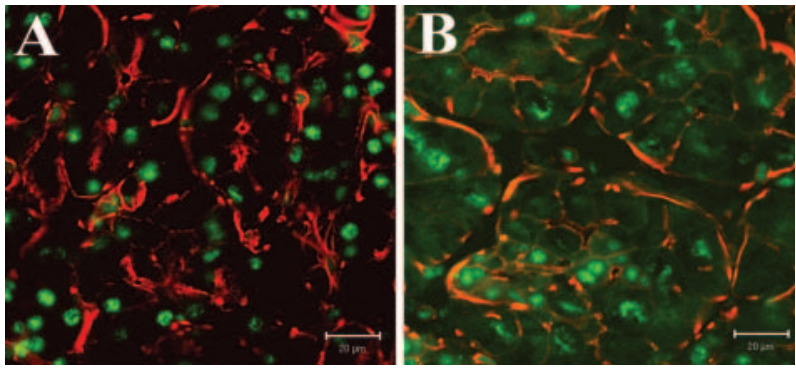

Figure 1 Representative confocal microphotographs demonstrating NF-kB (p65 subunit) staining (green) in LGs of young $(A)$ and aging $(B)$ rats. The red is phalloidin counterstaining, indicating the localization of actin in the acinar or ductal cell membrane. The findings are representative of two independent experiments ( $n=5$ /group). Scale bars, $20 \mu \mathrm{m}$.

measured by RIA. To ensure sensitivity, specificity and reproducibility of the method, the following procedures were performed: (i) curves with triplicate samples of commercially available insulin (Amersham Biosciences) were run in parallel, (ii) samples with similar dilutions of insulin-like growth factor-1 (Sigma) or containing buffer only were also analyzed and (iii) assay samples were run in duplicate. The sensitivity range was $0 \cdot 1-20 \mathrm{ng} / \mathrm{ml}$, and the interassay and intraassay coefficients of variation were estimated at $0 \cdot 11$ and $0 \cdot 076$, respectively.

\section{Statistical analysis}

Data are reported as means \pm S.E.M. Comparisons were made using the Mann-Whitney $U$ test (Statview Software, Abacus, CA, USA), with the level of significance set at $P<0 \cdot 05$

\section{Results}

Immunochemical localization of $N F-\kappa B, A G E s$ and $R A G E$

To locate and compare the expression of NF- $\kappa B$, AGEs and RAGE in LGs, samples from aging and control rats were processed in parallel and submitted to immunofluorescence by laser confocal microscopy ( $n=5$ animals/ group). Histological analysis demonstrated cytoplasmic and nuclear NF- $\kappa \mathrm{B}$ expression in acinar cells of LGs, with higher expression levels in nucleus and cytoplasm of LG acinar cells from aging animals compared with young on all slides examined (Fig.1). AGE expression was observed in LG tissue samples, with more intense staining in the plasma membrane and cytoplasm of acinar cells and connective tissue of aging rats in all samples analyzed (Fig. 2). RAGE protein was also identified in LG tissues, predominantly with plasma membrane distribution in ductal cells and more intensely expressed in aging than in young rats (Fig. 3). RAGE expression in corneal
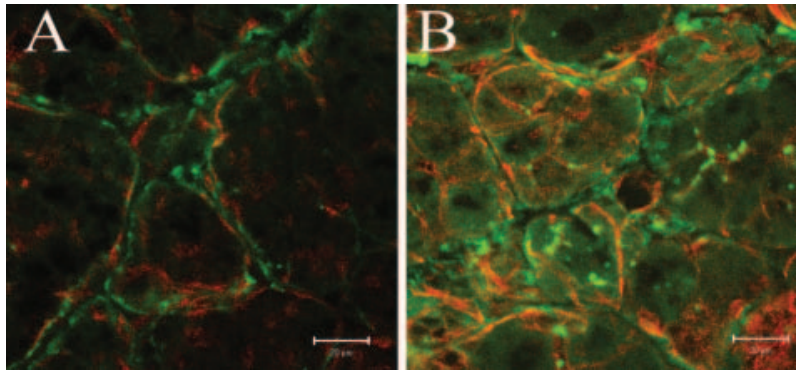

Figure 2 Representative confocal microphotographs demonstrating AGE staining (green) in LGs of young (A) and aging (B) rats. The findings are representative of two independent experiments ( $n=5 /$ group). Scale bars, $20 \mu \mathrm{m}$.

epithelium and stroma was also more intense in aging animals than in young, as observed on all slides from both groups (Fig. 4).

\section{$N F-\kappa B$ expression in aging and young $L G$ s}

$\mathrm{NF}-\kappa \mathrm{B}$ protein was detected in nuclear and cytoplasmic extracts of LGs, and higher levels of expression were

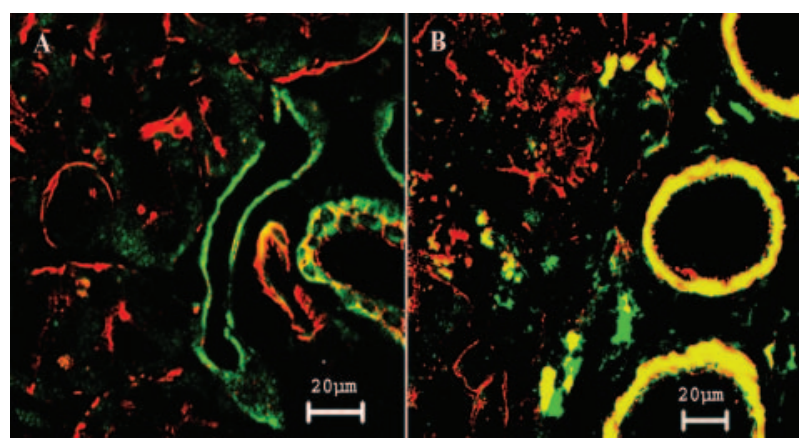

Figure 3 Representative confocal microphotographs demonstrating RAGE staining (green) in LGs of young (A) and aging (B) rats. The findings are representative of two independent experiments ( $n=5 /$ group). Scale bars, $20 \mu \mathrm{m}$.
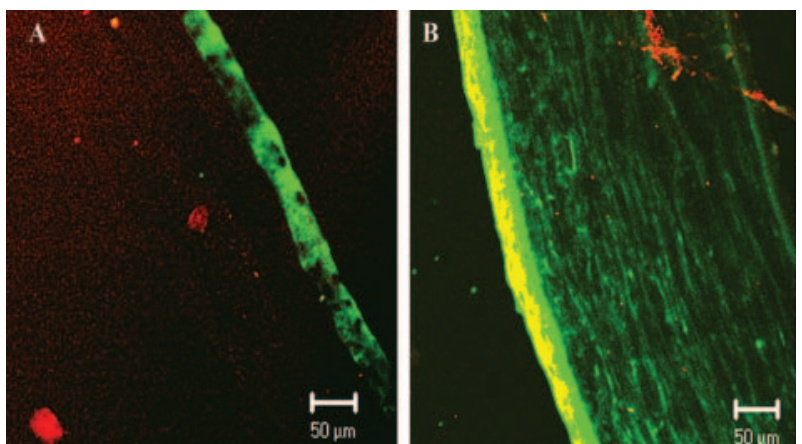

Figure 4 Representative confocal microphotographs demonstrating RAGE staining (green) in the cornea of control (left) and aging rats (right). The findings are representative of two independent experiments ( $n=5 /$ group). Scale bars, $50 \mu \mathrm{m}$. 

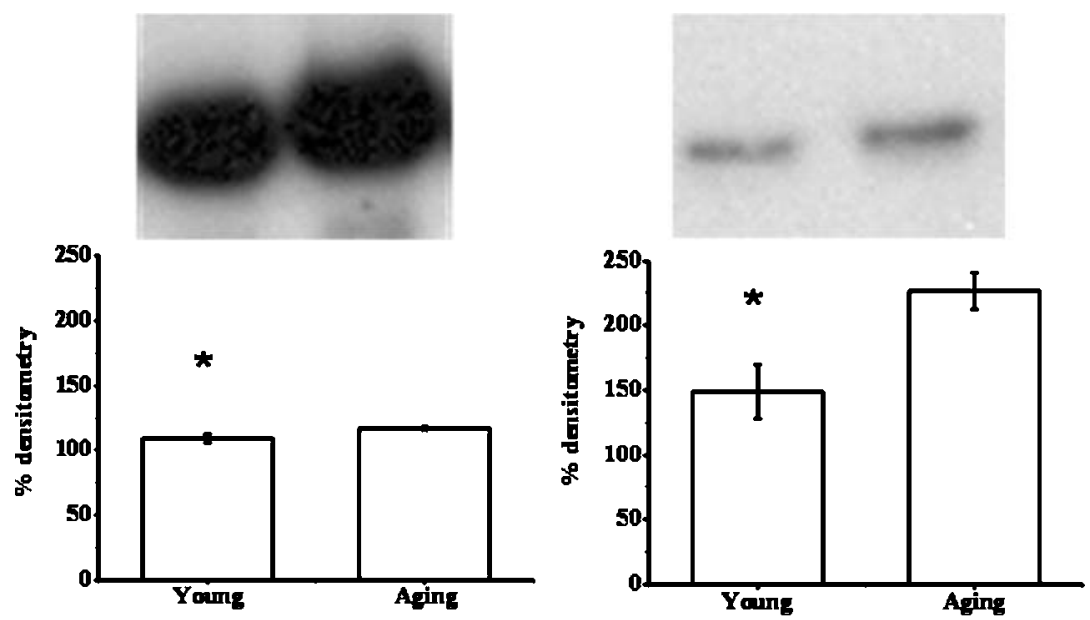

Figure 5 Effect of aging on NF- $\mathrm{kB}$ p65 expression in cytoplasmic (A) and nuclear (B) extracts of LGs. Cytoplasmic and nuclear extracts ( $n=6$ animals/group) were analyzed by Western blot using an anti-NF-кB antibody specific for the p65 subunit. Values are means \pm S.E.M. Values obtained for the young groups were defined as $100 \%$, and values obtained for aging animals are expressed as a percentage of this value. Results are representative of two independent experiments. Higher expression of NF- $\mathrm{KB}$ p65 was detected in nuclear and cytoplasmic extracts of aging animals $(P=0 \cdot 02)$.

detected in both nucleus and cytoplasmic extracts of aging animals compared with young $(n=6 /$ group; $P=0 \cdot 02$ in both cases). These results were confirmed in three independent experiments (Fig. 5).

\section{LG weight, tear volume and peroxidase activity}

Previous studies have demonstrated structural and functional changes in aging LGs (Bromberg \& Welch 1985, Sullivan et al. 1990, Draper et al. 1999, 2003, Rocha et al. 2003). To ensure that this was the case in the present animal model, LG weight, tear volume and LG peroxidase activity were determined. Results are given in Table 1. The mean peroxidase activity levels were twice as high in young than in aging LGs $(P=0 \cdot 016$; see Table 1 for details).

Table 1 Effect of aging on LG weight, body weight, basal tear volume, $\mathrm{K}_{\mathrm{ITT}}$, tear insulin level, IL-1 $\beta$ and TNF- $\alpha$ levels and peroxidase activity of Wistar male rats. Means \pm S.E.M. are shown

\begin{tabular}{|c|c|c|}
\hline & Aging & Young \\
\hline LG weight (mg) & $142 \cdot 60 \pm 12 \cdot 75^{*}$ & $77 \cdot 20 \pm 4.09$ \\
\hline Body weight (g) & $408 \cdot 8 \pm 18 \cdot 17^{*}$ & $280 \cdot 8 \pm 4 \cdot 65$ \\
\hline Tear volume $(\mu \mathrm{l})$ & $2 \cdot 40 \pm 0 \cdot 25 \dagger$ & $3 \cdot 96 \pm 0 \cdot 42$ \\
\hline $\mathrm{K}_{\mathrm{ITT}}$ & $3 \cdot 15 \pm 0 \cdot 04 \dagger$ & $4 \cdot 65 \pm 0.05$ \\
\hline Tear insulin (ng/ml) & $1 \cdot 56 \pm 0 \cdot 38$ & $0 \cdot 83 \pm 0 \cdot 32$ \\
\hline Tear IL-1 $\beta(p g / m l)$ & $6 \cdot 22 \pm 0 \cdot 15^{*}$ & $4 \cdot 26 \pm 0 \cdot 18$ \\
\hline Tear TNF- $\alpha(\mathrm{pg} / \mathrm{ml})$ & $239 \cdot 10 \pm 50 \cdot 02$ & $57 \cdot 32 \pm 12 \cdot 68$ \\
\hline Peroxidase activity $(\mu \mathrm{M} / \mathrm{min})$ & $38 \cdot 2 \pm 6 \cdot 7 \dagger$ & $69 \cdot 0 \pm 15 \cdot 0$ \\
\hline
\end{tabular}

${ }^{*} P<0 \cdot 05$, significantly higher than young; $\uparrow P<0 \cdot 05$, significantly lower than young. $n=5$ for all parameters, except for tear volume where $n=10$.

\section{Insulin, IL-1 $\beta$ and TNF- $\alpha$ levels in the tear film}

To investigate the metabolic and inflammatory consequences of aging for LGs, the content of insulin, IL-1 $\beta$ and TNF- $\alpha$ was measured. The tear film insulin secretion in fasted rats was similar in both groups, with a tendency to higher levels in 24-month-old rats although, the difference was not statistically significant (Table 1 ). Both IL-1 $\beta$ and TNF- $\alpha$ levels were significantly greater in aging rats $(P=0.007$ and 0.05 , respectively; Table 1$)$.

\section{In vitro insulin secretion}

To determine whether LGs isolated from aging rats responded with insulin secretion in a similar way to young rats, assays were conducted with isolated LG samples exposed for $1 \mathrm{~h}$ to media containing secretagogues such as increased glucose levels $(2 \cdot 8-16 \cdot 7 \mathrm{mM})$ and cholinergic (i.e. carbachol) or depolarizing (i.e. $\left.\mathrm{K}^{+}\right)$stimulation $(n=5$ / condition).

Mean insulin levels in the supernatant increased by $147 \%$ in medium containing $8.3 \mathrm{mM}$ glucose compared with medium containing $2.8 \mathrm{mM}$ glucose. Adding $200 \mu \mathrm{M}$ carbachol to the medium containing $8.3 \mathrm{mM}$ glucose increased the mean level of insulin by $59 \%$. Doubling the level of glucose in the medium from 8.3 to $16.7 \mathrm{mM}$ increased the insulin level by $58 \%$. The depolarizing effect of $40 \mathrm{mM} \mathrm{KCl}$ in medium containing $2.8 \mathrm{mM}$ glucose increased the insulin levels by $61 \%$ compared with $2.8 \mathrm{mM}$ glucose solely (Fig. 6). These experiments showed that insulin secretion in response to 


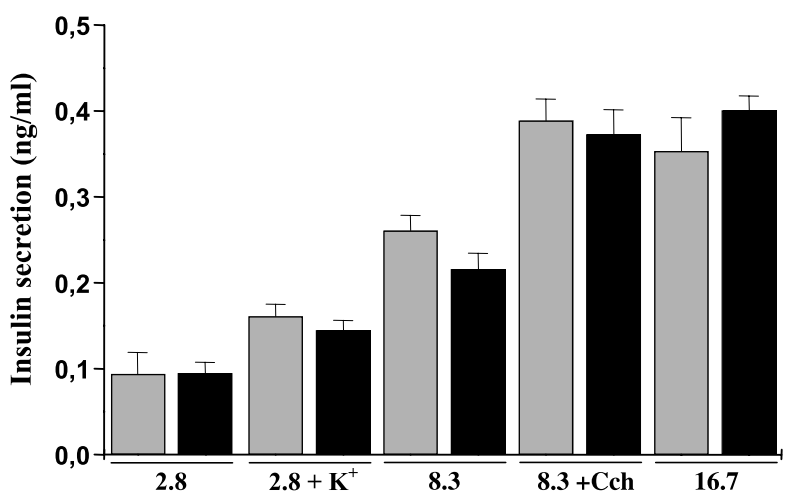

Figure 6 Insulin release $(\mathrm{ng} / \mathrm{ml})$ from samples containing two fragments of LG tissues from aging (black bars) and young (grey bars) Wistar rats, incubated under basal conditions $(2 \cdot 8 \mathrm{mM}$ glucose; 2.8$)$ or stimulated with 8.3 or $16.7 \mathrm{mM}$ glucose $(8 \cdot 3$, $16 \cdot 7), 200 \mu \mathrm{M}$ carbachol plus $8 \cdot 3 \mathrm{mM}$ glucose $(8 \cdot 3+\mathrm{Cch})$, or $40 \mathrm{mM} \mathrm{KCl}$ plus $2 \cdot 8 \mathrm{mM}$ glucose $\left(2 \cdot 8+\mathrm{K}^{+}\right)$for $1 \mathrm{~h}$. Data are representative of at least three independent experiments $(n=5$ samples/condition) and results are expressed as means \pm S.E.M

higher glucose levels $(2 \cdot 8-16.7 \mathrm{mM})$ or to $200 \mu \mathrm{M}$ carbachol or $40 \mathrm{mM} \mathrm{K}^{+}$behaved in a similar manner, with no statistical significance between groups.

Similar assays performed with pancreatic islets revealed that the insulin secretion response to low $(2 \cdot 8 \mathrm{mM})$ or physiologic $(8.3 \mathrm{mM})$ levels of glucose was reduced in aged animals, but was slightly higher in response to higher levels of glucose $(16.7 \mathrm{mM} ; P=0.02,0.021$ and 0.08 , respectively), and was similar when stimulated with $200 \mu \mathrm{M}$ carbachol or $40 \mathrm{mM} \mathrm{K}^{+}$(Fig. 7).

Comparison of total insulin content in LG tissue samples obtained from aging and young rats showed levels of $14.44 \pm 2.80$ and $16.06 \pm 2.12 \mathrm{ng} / \mathrm{ml}$, respectively $(P=0 \cdot 81)$. The mean level in pancreatic islet samples was

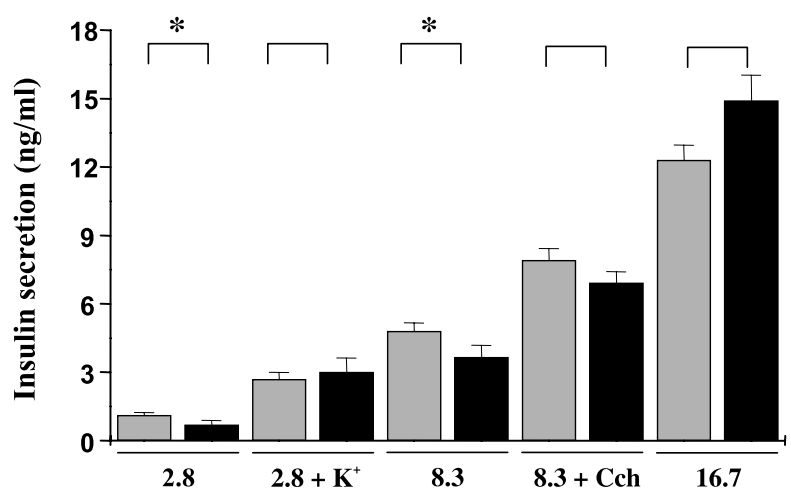

Figure 7 Insulin concentration $(\mathrm{ng} / \mathrm{ml})$ in the supernatant of pancreatic islets of aging (black bars) and young (grey bars) rats incubated under basal conditions $(2 \cdot 8 \mathrm{mM}$ glucose) or stimulated with 8.3 and $16.7 \mathrm{mM}$ glucose, $200 \mu \mathrm{M}$ carbachol plus $8.3 \mathrm{mM}$ glucose, or $40 \mathrm{mM} \mathrm{KCl}$ plus $2 \cdot 8 \mathrm{mM}$ glucose for $1 \mathrm{~h}$ (column labels are as for Fig. 6). Data are representative of at least three independent experiments ( $n=5$ samples/condition) and results are expressed as means \pm S.E.M. ${ }^{*} P<0 \cdot 05$, young versus aging rats.
$1075 \cdot 0 \pm 106 \cdot 10$ and $1738 \cdot 0 \pm 150 \cdot 0 \mathrm{ng} / \mathrm{sample}$ in the young and aging groups, respectively $(P=0 \cdot 007)$.

\section{Discussion}

The lower tear volume and peroxidase activity described here indicate a reduced secretory capacity with aging in rats, as reported previously (Bromberg \& Welch 1985, Sullivan et al. 1990, Draper et al. 1999). In the present study, we demonstrated the presence of high levels of AGE and RAGE expression in LGs and RAGE in corneas of aging compared with young rats. Previous studies have reported that these mediators accumulate as a consequence of chronic hyperglycemia, are involved in widespread age-related pathology, and correlate with impaired hormone and growth factor signaling impairment, proinflammatory mediator recruitment and vascular damage (Vlassara et al. 1994, Stitt 2001, Portero-Otin et al. 2002).

In the present study, the mean LG weight of 24-monthold rats was significantly higher than in 2-month-old rats. This finding, apparently in conflict with a reduction in various functional parameters, may be explained by the acinar area replacement by connective tissue and reduction of metabolic, vascular and neural inputs over the secretory tissue. By 3 months of age, in spite of a stabilization, after a rapid increase in the LG weight there is a reduction in acinar density and the capacity to respond to cholinergic stimulation (Sullivan et al. 1990, Draper et al. 1999).

Although higher levels of NF- $\mathrm{KB}$ expression were clearly demonstrated in the nuclear area of acinar cells in aging LGs, we could only demonstrate a trend towards higher levels of NF- $\kappa B$-induced downstream proinflammatory cytokines such as IL- $1 \beta$ and TNF- $\alpha$ in the tear film of aged rats. This finding may be explained, at least in part, by the wide range of values obtained in the assays for these cytokines. Since inflammation has been linked previously to age-related LG dysfunction in humans, and the expression of AGEs and NF- $\kappa B$ leads to an increase in the production of these proinflammatory cytokines, it is our opinion that further studies are necessary before the contribution of these inflammatory mediators to LG dysfunction in aging is definitely ruled out (Damato et al. 1984, Evans et al. 2002).

Insulin secretion by the LGs has been described previously, and is believed to be a mechanism by which this hormone is delivered to the ocular surface through the tear film (Rocha et al. 2002a). Therefore, our hypothesis was that LG dysfunction of aging would be associated with impairment of insulin secretion. In fact, old rats have higher insulin levels in pancreatic islets and blood, but they are heavier and have a reduced capacity for glucose storage, as observed here and elsewhere (Rocha et al. 2003). In a previous study, we have shown that aging is accompanied by reduced tyrosine kinase activity of the insulin receptor in LGs, an event that also occurs in liver, muscle and the central nervous system and may account in 
part for the dysfunction of these tissue, indicating a lower capacity of insulin intake and secretion by exocrine glands (Carvalho et al. 1996). These phenomena may be explained by the reduced capacity of response of pancreatic $\beta$-cells and by the insulin resistance occurring in aging (Castro et al. 1993, Carvalho et al. 1996, Rocha et al. 2003, 2004). However, the similarity of insulin content and secretion by LGs in the aging and young groups may suggest mechanisms to preserve the levels offered to the LGs and ocular surface, and supports the theory that this hormone is a key element for LGs and ocular surface maintenance (Hann et al. 1991).

In conclusion, this study provides evidence for the hypothesis that the cumulative formation of AGEs and RAGEs, and the activation of NF- $\mathrm{KB}$, may be involved in the physiopathology of LG dysfunction of aging. Moreover, it confirms previous findings that metabolic alterations may lead to these dysfunctions, although insulin resistance does not impair insulin secretion by LGs in this model. Ongoing studies will help to elucidate whether any of these steps could be a target for therapeutic interventions that could avoid or reverse these events.

\section{Funding}

This work was supported by Fundação de Amparo a Pesquisa do Estado de São Paulo (FAPESP) and CNPq. The authors declare that there is no conflict of interest that would prejudice the impartiality of this scientific work.

\section{References}

Boschero AC, Szpak-Glasman M, Carneiro EM, Bordin S, Paul I, Rojas E \& Atwater I 1995 Oxotremorine-m potentiation of glucose-induced insulin release from rat islets involves M3 muscarinic receptors. American Journal of Physiology - Endocrinology and Metabolism 268 E336-E342.

Bromberg BB \& Welch MH 1985 Lacrimal protein secretion: comparison of young and old rats. Experimental Eye Research $\mathbf{4 0}$ $313-320$

Carvalho CR, Brenelli SL, Silva AC, Nunes AL, Velloso LA \& Saad MJ 1996 Effect of aging on insulin receptor, insulin receptor substrate-1, and phosphatidylinositol 3-kinase in liver and muscle of rats. Endocrinology 137 151-159.

Castro M, Pedrosa D \& Osuna JI 1993 Impaired insulin release in aging rats: metabolic and ionic events. Experientia 49 850-853.

Damato BE, Allan D, Murray SB \& Lee WR 1984 Senile atrophy of the human lacrimal gland: the contribution of chronic inflammatory disease. British Journal of Ophthalmology 68 674-680.

Draper CE, Adeghate EA, Singh J \& Pallot DJ 1999 Evidence to suggest morphological and physiological alterations of lacrimal gland acini with ageing. Experimental Eye Research 68 265-276.

Draper CE, Singh J \& Adeghate E 2003 Effects of age on morphology, protein synthesis and secretagogue-evoked secretory responses in the rat lacrimal gland. Molecular and Cellular Biochemistry $2487-16$

Evans JL, Goldfine ID, Maddux BA \& Grodsky GM 2002 Oxidative stress and stress-activated signaling pathways: a unifying hypothesis of type 2 diabetes. Endocrine Reviews 23 599-622.
Hann LE, Kelleher RS \& Sullivan DA 1991 Influence of culture conditions on the androgen control of secretory component production by acinar cells from the rat lacrimal gland. Investigative Ophthalmology and Visual Sciences 32 2610-2621.

Mathers WD, Lane JA \& Zimmerman MB 1996 Tear film changes associated with normal aging. Cornea 15 229-234.

McGill JI, Liakos GM, Goulding N \& Seal DV 1984 Normal tear protein profiles and age-related changes. British Journal of Ophthalmology 68 316-320.

Paez-Espinosa EV, Rocha EM, Velloso LA, Boschero AC \& Saad MJ 1999 Insulin-induced tyrosine phosphorylation of Shc in liver, muscle and adipose tissue of insulin resistant rats. Molecular and Cellular Endocrinology 156 121-129.

Perfetti R, Rafizadeh CM, Liotta AS \& Egan JM 1995 Age-dependent reduction in insulin secretion and insulin mRNA in isolated islets from rats. American Journal of Physiology - Endocrinology and Metabolism 269 E983-E990.

Pongor S, Ulrich PC, Bencsath FA \& Cerami A 1984 Aging of proteins: isolation and identification of a fluorescent chromophore from the reaction of polypeptides with glucose. PNAS $\mathbf{8 1}$ $2684-2688$.

Portero-Otin M, Pamplona R, Bellmunt MJ, Ruiz MC, Prat J, Salvayre R \& Negre-Salvayre A 2002 Advanced glycation end product precursors impair epidermal growth factor receptor signaling. Diabetes 51 1535-1542.

Rocha EM, Wickham LA, Huang Z, Toda I, Gao J, da Silveira LA \& Sullivan DA 1998 Presence and testosterone influence on the levels of anti- and pro-inflammatory cytokines in lacrimal tissues of a mouse model of Sjogren's syndrome. Advances in Experimental Medicine and Biology 438 485-491.

Rocha EM, de MLMH, Carvalho CR, Saad MJ \& Velloso LA 2000 Characterization of the insulin-signaling pathway in lacrimal and salivary glands of rats. Current Eye Research 21 833-842.

Rocha EM, Cunha DA, Carneiro EM, Boschero AC, Saad MJ \& Velloso LA 2002a Identification of insulin in the tear film and insulin receptor and IGF-1 receptor on the human ocular surface. Investigative Ophthalmology and Visual Sciences 43 963-967.

Rocha EM, Hirata AE, Carneiro EM, Saad MJ \& Velloso LA $2002 b$ Impact of gender on insulin signaling pathway in lacrimal and salivary glands of rats. Endocrine 18 191-199.

Rocha EM, Carvalho CR, Saad MJ \& Velloso LA 2003 The influence of ageing on the insulin signalling system in rat lacrimal and salivary glands. Acta Ophthalmologica Scandinavica 81 639-645.

Rocha EM, Fernandes MLA \& Velloso LA 2004 Insulin signaling in aging nervous system. In Advances in Cell Aging and Gerontology: Protein Phosphorylation in Aging and Age-Related Disease, vol. 16, pp 107-132. Ed. MP Mattson. Amsterdam: Elsevier.

Schein OD, Munoz B, Tielsch JM, Bandeen-Roche K \& West S 1997 Prevalence of dry eye among the elderly. American Journal of Ophthalmology 124 723-728.

Singh R, Barden A, Mori T \& Beilin L 2001 Advanced glycation end-products: a review. Diabetologia 44 129-146.

Solomon A, Dursun D, Liu Z, Xie Y, Macri A \& Pflugfelder SC 2001 Pro- and anti-inflammatory forms of interleukin-1 in the tear fluid and conjunctiva of patients with dry-eye disease. Investigative Ophthalmology and Visual Sciences 42 2283-2292.

Stitt AW 2001 Advanced glycation: an important pathological event in diabetic and age related ocular disease. British Journal of Ophthalmology 85 746-753.

Stoppiglia LF, Nogueira TA, Leite AR, Carneiro EM \& Boschero AC 2002 Protective effect of D-glucose, L-leucine and fetal calf serum against oxidative stress in neonatal pancreatic islets. Biochimica et Biophysica Acta 1588 113-118.

Sullivan DA, Hann LE, Yee L \& Allansmith MR 1990 Age- and gender-related influence on the lacrimal gland and tears. Acta Ophthalmologica (Copenhagen) 68 188-194.

Vaisse C, Halaas JL, Horvath CM, Darnell Jr JE, Stoffel M \& Friedman JM 1996 Leptin activation of Stat3 in the hypothalamus 
of wild-type and ob/ob mice but not $\mathrm{db} / \mathrm{db}$ mice. Nature Genetics 14 95-97.

Vlassara H, Bucala R \& Striker L 1994 Pathogenic effects of advanced glycosylation: biochemical, biologic, and clinical implications for diabetes and aging. Laboratory Investigation 70 138-151.

Zarina S, Zhao HR \& Abraham EC 2000 Advanced glycation end products in human senile and diabetic cataractous lenses. Molecular and Cellular Biochemistry 210 29-34.
Zoukhri D, Hodges RR, Byon D \& Kublin CL 2002 Role of proinflammatory cytokines in the impaired lacrimation associated with autoimmune xerophthalmia. Investigative Ophthalmology and Visual Sciences 43 1429-1436.

Received in final form 2 July 2005

Accepted 13 July 2005 